\title{
ANALISIS SALURAN EKSISTING DI KELURAHAN PADEMANGAN TIMUR
}

\author{
Felix Jayanto ${ }^{1}$ dan Wati Asriningsih Pranoto
}

\author{
${ }^{1}$ Program Studi Sarjana Teknik Sipil, Universitas Tarumanagara, Jl. Letjen S. Parman No.1 Jakarta \\ felix.325160182@stu.untar.ac.id \\ ${ }^{2}$ Program Studi Magister Teknik Sipil, Universitas Tarumanagara, Jl. Letjen S. Parman No.1 Jakarta \\ watip@ft.untar.ac.id
}

\begin{abstract}
Flooding is not a strange thing anymore for DKI Jakarta Province. Many factors cause flooding in DKI Jakarta Province, such as heavy rain, blockage of drainage channels by garbage, tides, flooding from higher areas, and others. Lots of losses were caused by this flood, such as damaged roads. Public facilities are also damaged, causing temporary economic paralysis, many residents are sick, it can even cause fatalities. In Pademangan District, several areas are prone to flooding, but strangely, in East Pademangan Village, there is only one place that is affected by floods. The flood in that place has a depth of about $20 \mathrm{~cm}$. So it is necessary to explore why only that place is affected by floods, so that a solution can be found. For that there are several things that need to be analyzed, namely rainfall, channel capacity and the condition of the existing channel. After analyzing everything, it can be concluded that the East Pademangan area is caused by the existing channel capacity which is still unable to accommodate high rainfall. Apart from that, garbage and sediment also cause flooding in this area.
\end{abstract}

Keywords: flood; drainage; rainfall; Pademangan

\begin{abstract}
ABSTRAK
Banjir bukan merupakan hal yang aneh lagi untuk Provinsi DKI Jakarta. Ada banyak faktor yang menyebabkan banjir di Provinsi DKI Jakarta seperti hujan deras, penyumbatan saluran drainase oleh sampah - sampah, pasang surut air laut, banjir kiriman dari daerah yang lebih tinggi, dan lain - lain. Banyak sekali kerugian yang ditimbulkan akibat banjir ini; seperti jalan banyak yang rusak, fasilitas - fasilitas umum juga ikut rusak, menyebabkan kelumpuhan ekonomi sesaat, warga banyak yang sakit, bahkan bisa menimbulkan jatuhnya korban jiwa. Di Kecamatan Pademangan terdapat beberapa daerah yang rawan banjir, tetapi anehnya di Kelurahan Pademangan Timur hanya ada satu tempat yang terkena genangan banjir. Banjir di tempat tersebut memiliki kedalaman sekitar $20 \mathrm{~cm}$. Maka perlu ditelusuri mengapa hanya di tempat itu saja yang terkena genangan banjir, sehingga bisa dicari solusinya. Untuk itu ada beberapa hal yang perlu dianalisis yaitu curah hujan, kapasitas saluran dan keadaan saluran eksisting. Setelah dianalisis dapat disimpulkan bahwa daerah Pademangan Timur ini disebabkan oleh kapasitas saluran eksisting yang masih belum bisa menampung curah hujan yang tinggi. Selain itu, sampah dan sedimen juga menjadi penyebab banjir di daerah ini.
\end{abstract}

Kata kunci: banjir; drainase; curah hujan; Pademangan

\section{PENDAHULUAN}

\section{Latar belakang}

Di Kelurahan Pademangan Timur sebagian besar daerahnya merupakan pemukiman dan objek perekonomian. Namun tidak semua wilayah di Kelurahan Pademangan Timur ini terkena genangan air. Terdapat dua periode genangan banjir yang terjadi di Kelurahan Pademangan Timur. Yang pertama pada 24 Januari 2020, dan yang terakhir mengalami genangan air yang cukup lama yakni pada 24 Februari 2020 sampai dengan 25 Februrari 2020. Oleh karena itu, perlu dianalisis mengapa hanya gang tersebut yang terkena genangan air ini. Tujuan dari penulisan skripsi ini adalah menganalisis saluran eksisting untuk mengetahui penyebab genangan banjir yang terjadi di sebagian wilayah Kelurahan Pademangan Timur sehingga bisa dicari cara untuk mengatasi banjir.

\section{Drainase}

Drainase mempunyai arti mengalirkan, menguras, membuang, atau mengalihkan air. Secara umum, drainase didefinisikan sebagai serangkain bangunan air yang berfungsi untuk mengurangi dan membuang kelebihan air dari 
Timur

suatu kawasan atau lahan, sehingga lahan tersebut dapat difungsikan secara optimal. Drainase juga dapat diartikan sebagai suatu cara pembuangan kelebihan air yang tidak diinginkan pada suatu daerah, serta cara penanggulangan akibat yang ditimbulkan oleh kelebihan air tersebut. (Suripin, 2004)

\section{Hujan rencana}

Ada empat jenis distribusi yang banyak digunakan dalam menghitung curah hujan rencana yaitu (SNI 2415:2016):

- Distribusi Normal

Persamaan distribusi normal dapat dilihat sebagai berikut:

$$
\mathrm{X}_{\mathrm{t}}=\overline{\mathrm{X}}+\mathrm{z} \cdot \mathrm{S}_{\mathrm{x}}
$$

dengan $\mathrm{X}_{\mathrm{t}}=$ curah hujan rencana ( $\mathrm{mm} /$ hari $), \bar{X}=$ curah hujan maksimum rata-rata $(\mathrm{mm} / \mathrm{hari}), \mathrm{S}_{\mathrm{x}}=$ standar deviasi, $\mathrm{z}=$ faktor frekuensi.

- Distribusi Log Normal

Persamaan distribusi log normal dapat dilihat sebagai berikut:

$$
\log X_{t}=\bar{X}+K_{t} \cdot S_{x}
$$

dengan $\mathrm{X}_{\mathrm{t}}=$ curah hujan rencana $(\mathrm{mm} /$ hari $), \bar{X}=$ curah hujan maksimum rata-rata $(\mathrm{mm} / \mathrm{hari}), \mathrm{S}_{\mathrm{x}}=$ standar deviasi, $\mathrm{K}_{\mathrm{t}}=$ standar variabel untuk periode ulang.

- Log Pearson III

Persamaan distribusi log pearson III dapat dilihat sebagai berikut:

$$
\log \overline{\mathrm{X}}=\frac{\sum_{\mathrm{i}=1}^{\mathrm{n}} \log \left(\mathrm{X}_{\mathrm{i}}\right)}{\mathrm{n}}
$$

dengan $\log \bar{X}=$ harga rata-rata logaritmik (mm/hari), $\mathrm{X}_{\mathrm{i}}=$ nilai curah hujan (mm/hari), $\mathrm{n}=$ jumlah data.

- Gumbel

Persamaan distribusi gumbel dapat dilihat sebagai berikut:

$$
X_{t}=\bar{x}+\frac{\left(Y_{t}-Y_{n}\right)}{S_{n}} \times S_{x}
$$

dengan $\mathrm{X}_{\mathrm{t}}=$ curah hujan rencana $(\mathrm{mn} / \mathrm{hari}), \bar{X}=$ curah rata-rata $(\mathrm{mm} /$ hari $), \mathrm{S}_{\mathrm{x}}=$ standar deviasi, $\mathrm{Y}_{\mathrm{t}}=$ reduced variable, $\mathrm{Y}_{\mathrm{n}}=$ reduced mean, $\mathrm{S}_{\mathrm{n}}=$ reduced standard deviation.

\section{Pemilihan fungsi distribusi}

Pemilihan fungsi distribusi dapat diuji dengan uji kecocokan menggunakan metode pengujian dan dengan confidence interval tertentu dapat menggunakan Metode Chi-Square dan Metode Kolmogorov-Smirnov sebagai berikut (SNI 2415:2016):

- Chi-Square

Metode ini menganggap pengamatan membentuk variable acak dan dilakukan secara statistik dengan mengikuti kurva distribusi chi-square dengan derajat kebebasan tertentu. Uji kecocokan ini dapat dilihat pada persamaan:

$$
X^{\frac{k}{(i=1)}}=\frac{(O i-E i)^{2}}{E i}
$$

dengan $X^{\frac{k}{(i=1)}}=$ parameter chi-square terhitung, $\mathrm{k}=$ jumlah sub kelompok, $\mathrm{O} i=$ jumlah nilai pengamatan pada sub kelompok ke I, Ei = jumlah nilai teoritis pada sub kelompok ke i.

- Kolmogorov-Smirnov

Untuk menghindari hilangnya informasi data pada uji chi-square akibat pengelompokan data dalam kelas-kelas interval, ada beberapa metode lain yang dikembangkan. Salah satu metode yang sering digunakan adalah uji Kolmogorov-Smirnov. Persamaan untuk Kolmogorov - Smirnov tertera sebagai berikut:

$$
\operatorname{Dn}=\max |\mathrm{P}(\mathrm{x})-\mathrm{Po}(\mathrm{x})|
$$

dengan $\mathrm{Dn}=$ jarak vertical pengamatan, $\mathrm{P}(\mathrm{x})=$ probabilitas sampel, $\mathrm{Po}(\mathrm{x})=$ probabilitas dari teoritisnya. 


\section{Intensitas hujan}

Intensitas hujan adalah besaran ketinggian hujan yang ditetapkan sebagai harga perencanaan yang memperhatikan periode ulang yang dihitung dengan metode yang lazim dalam analisis hidrologi (SNI 8456:2017). Menurut Dr. Mononobe jika data curah hujan yang ada hanya curah hujan harian. Rumus yang digunakan:

$$
I=\frac{R_{24}}{24}\left(\frac{24}{t_{c}}\right)^{\frac{2}{3}}
$$

dengan $\mathrm{I}=$ intensitas hujan $(\mathrm{mm} / \mathrm{jam})$, tc = durasi hujan (jam), R24 = curah hujan maksimum dalam 24 jam $(\mathrm{mm})$.

\section{Koefisien Limpasan (C)}

Nilai Koefisien Limpasan dapat dilihat pada Tabel 1.

Tabel 1. Koefisien limpasan

\begin{tabular}{lcc}
\hline Tata Guna Lahan & Karakteristik & Koefisien Limpasan (C) \\
\hline Pusat bisnis dan perbelanjaan & Penuh & 0,9 \\
Industri & $20 \mathrm{rumah} / \mathrm{ha}$ & 0,8 \\
& $30 \mathrm{rumah} / \mathrm{ha}$ & 0,48 \\
Perumahan (kepadatan sedang - tinggi) & $40 \mathrm{rumah} / \mathrm{ha}$ & 0,55 \\
& $50 \mathrm{rumah} / \mathrm{ha}$ & 0,65 \\
Perumahan (kepadatan rendah) & $10 \mathrm{rumah} / \mathrm{ha}$ & 0,75 \\
Taman & Daerah datar & 0,4 \\
Parkir & & 0,3 \\
(Sumber: SNI 2415:2016) & & 0,95 \\
\hline
\end{tabular}

Dari Tabel 1 digunakan kofisien limpasan 0,6 karena Kepadatan Perumahan di Kelurahan Pademangan Timur adalah 30 sampai dengan $40 \mathrm{rumah} / \mathrm{ha}$.

\section{Debit limpasan}

Untuk menghitung debit limpasan dapat digunakan persamaan menurut (SNI 2415:2016) sebagai berikut:

$$
\mathrm{Qp}=0,00278 \text { C.I.A }
$$

Dengan Qp = debit puncak banjir $\left(\mathrm{m}^{3} / \mathrm{s}\right), \mathrm{C}=$ koefisien limpasan, I = intensitas hujan selama waktu konsentrasi $(\mathrm{mm} / \mathrm{jam}), \mathrm{A}=$ Luas daerah aliran $(\mathrm{Ha})$.

\section{METODE PENELITIAN}

Metode penelitian akan dilaksanakan dengan tahapan dibawah ini.

\section{Pengumpulan data}

Dalam penelitian ini, data yang diperlukan:

- Data curah hujan harian maksimum Badan Meteorologi Klimatologi dan Geofisika Indonesia selama 10 tahun.

- Peta topografi Kecamatan Pademangan dari Dinas Cipta Karya, Tata Ruang, dan Pertanahan Provinsi DKI Jakarta.

- Peta sebaran titik banjir, jaringan drainase, dan peta arah aliran drainase Kecamatan Pademangan dari Suku Dinas Sumber Daya Air Kota Administrasi Jakarta Utara.

- Spesifikasi saluran drainase Kecamatan Pademangan dari Suku Dinas Sumber Daya Air Kecamatan Pademangan, Jakarta Utara. 


\section{Pengolahan data}

Pengolahan data yang dilakukan adalah sebagai berikut:

- Mengambil data curah hujan maksimum harian setiap tahun.

- Melakukan pengujian kecocokan fungsi distribusi dengan menggunakan metode Chi-Square dan Kolmogorov-Smirnov.

- Melakukan perhitungan curah hujan rencana dengan metode yang sudah ditentukan dari pengujian distribusi.

- Menghitung debit limpasan dengan metode Rasional.

- Menghitung kapasitas saluran drainase eksisting.

- Menentukan saluran mana yang sudah tidak bisa menampung debit limpasan.

- Melakukan desain ulang pada saluran yang tidak bisa menampung debit limpasan.

\section{HASIL DAN PEMBAHASAN}

\section{Peta jaringan drainase dan daerah tangkapan air}

Berikut adalah peta jaringan drainase dan daerah tangkapan air di wilayah Pademangan 2 Gang 22.

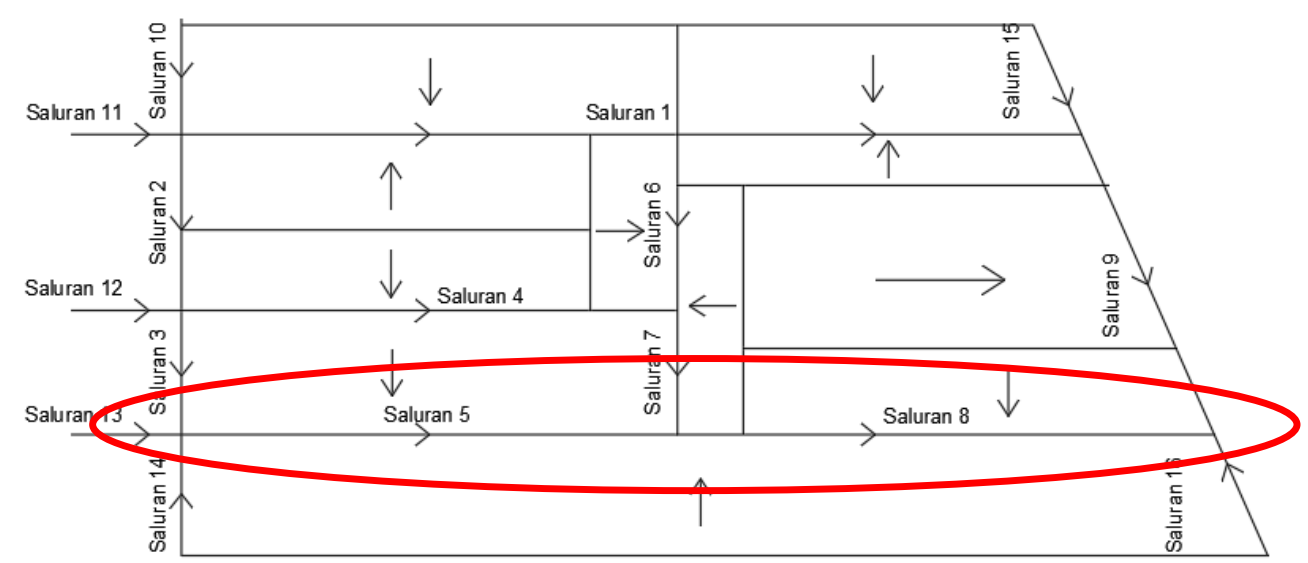

Gambar 1. Peta Jaringan drainase dan daerah tangkapan air (Sumber: Suku Dinas Sumber Daya Air Kota Administrasi Jakarta Utara)

Pada Gambar 1 terdapat Peta Jaringan Drainase dari Kelurahan Pademangan Timur, panah yang berada di antara garis menunjukkan arah aliran air, panah yang berada didalam kotak menunjukkan daerah tangkapan air, dan lingkaran merah menunnjukkan daerah rawan banjir.

\section{Perhitungan curah hujan rencana}

Dilakukan pemilihan fungsi distribusi menggunakan metode Chi-Square dan Kolmogorov-Smirnov yang tertulis pada Tabel 2 .

Tabel 2. Uji Chi-Square dan Kolmogorov-Smirnov

\begin{tabular}{llllllll}
\hline \multirow{2}{*}{ No } & \multirow{2}{*}{ Distribusi } & \multicolumn{2}{c}{ Chi-Square } & \multirow{2}{*}{ Kolmogorov-Smirnov } & \multirow{2}{*}{ Kesimpulan } \\
& & $\mathrm{X}^{2}$ & $\mathrm{X}^{2} \mathrm{Cr}$ & & Do & Dmax & \\
\hline 1 & Normal & 5,991 & 16 & Tidak Diterima & 0,41 & 0,1823 & Diterima \\
2 & Log Normal & 5,991 & 1 & Diterima & 0,41 & 0,1442 & Diterima \\
3 & Log Pearson III & 5,991 & 0 & Diterima & 0,41 & 0,1305 & Diterima \\
4 & Gumbel & 5,991 & 7 & Tidak Diterima & 0,41 & 0,4562 & Tidak Diterima \\
\hline
\end{tabular}


Dari rekapitulasi pada Tabel 2 didapat bahwa distribusi yang akan digunakan adalah distribusi Log Pearson III. Pengujian Distribusi yang dapat diterima adalah jika $\mathrm{X}^{2}$ lebih besar dari $\mathrm{X}^{2} \mathrm{Cr}$ pada Chi-Square dan Do lebih besar dari Dmax pada Kolmogorov-Smirnov.

Hasil perhitungan curah hujan rencana dengan metode Log Pearson III terdapat pada Tabel 3.

Tabel 3. Curah hujan rencana

\begin{tabular}{cccc}
\hline Periode Ulang & $\mathrm{K}$ & $\log \mathrm{Rr}$ & $\mathrm{Rr}(\mathrm{mm})$ \\
\hline 2 & $-0,033$ & 2,124095 & 133,07 \\
5 & 0,842 & 2,254952 & 179,87 \\
10 & 1,282 & 2,320754 & 209,29 \\
20 & 1,751 & 2,390893 & 245,98 \\
\hline
\end{tabular}

Berdasarkan Permen PU Nomor 12/PRT/M/2014 tentang Penyelenggaraan Sistem Drainase Perkotaan, periode ulang yang digunakan untuk daerah tangkapan air kurang dari 10 Ha di kota metropolitan adalah 2 tahun (Kementerian Pekerjaan Umum).

\section{Analisis saluran eksisting}

Debit saluran eksisting dihitung dengan metode Manning dan debit limpasan menggunakan metode Rasional. Hasil analisis saluran eksisting dapat dilihat pada Tabel 4.

Tabel 4. Analisis saluran eksisting

\begin{tabular}{|c|c|c|c|c|c|c|}
\hline \multirow{2}{*}{ No } & \multirow{2}{*}{ Posisi } & \multicolumn{2}{|c|}{ Saluran } & \multirow{2}{*}{ Debit Limpasan } & \multirow{2}{*}{ Debit Esisting } & \multirow{2}{*}{ Keterangan } \\
\hline & & Lebar Ek. & Kedalaman Ek. & & & \\
\hline \multirow{2}{*}{1} & Kiri & 0,7 & 0,6 & 0,3456 & 0,1714 & TIDAK MEMENUHI \\
\hline & Kanan & 0,8 & 0,8 & 0,0554 & 0,3281 & MEMENUHI \\
\hline \multirow{2}{*}{2} & Kiri & 0,5 & 0,6 & 0,0209 & 0,0767 & MEMENUHI \\
\hline & Kanan & 0,5 & 0,6 & 0,1082 & 0,0767 & TIDAK MEMENUHI \\
\hline \multirow{2}{*}{3} & Kiri & 1,1 & 1 & 0,0194 & 0,6068 & MEMENUHI \\
\hline & Kanan & 0,35 & 0,7 & 0,4638 & 0,0626 & TIDAK MEMENUHI \\
\hline \multirow{2}{*}{4} & Kiri & 0,6 & 0,8 & 0,0286 & 0,1554 & MEMENUHI \\
\hline & Kanan & 0,6 & 0,8 & 0,0226 & 0,1554 & MEMENUHI \\
\hline \multirow{3}{*}{5} & Kiri & 1,1 & 1,1 & 0,7085 & 0,6176 & TIDAK MEMENUHI \\
\hline & Kanan & 0,9 & 1 & 0,2125 & 0,4229 & MEMENUHI \\
\hline & Kiri & & & & & \\
\hline \multirow{2}{*}{6} & Kanan & 0,7 & 0,7 & 0,0332 & 0,1446 & MEMENUHI \\
\hline & Kiri & & & & & \\
\hline 7 & Kanan & 0,7 & 0,8 & 0,0416 & 0,2729 & MEMENUHI \\
\hline \multirow{2}{*}{8} & Kiri & 2 & 1,2 & 0,7315 & 1,5005 & MEMENUHI \\
\hline & Kanan & 0,9 & 1 & 0,2172 & 0,4229 & MEMENUHI \\
\hline \multirow{3}{*}{9} & Kiri & & & & & \\
\hline & Kanan & 1 & 1,1 & 0,3884 & 0,5421 & MEMENUHI \\
\hline & Kiri & & & & & \\
\hline 14 & Kanan & 0,7 & 0,6 & 0,0270 & 0,1212 & MEMENUHI \\
\hline 16 & $\begin{array}{l}\text { Kiri } \\
\text { Kanan }\end{array}$ & 0,8 & 0,6 & 0,1280 & 0,1771 & MEMENUHI \\
\hline 17 & $\begin{array}{l}\text { Kiri } \\
\text { Kanan }\end{array}$ & 0,8 & 0,8 & 0,1083 & 0,2320 & MEMENUHI \\
\hline
\end{tabular}

Dari rekapitulasi pada Tabel 4 didapat bahwa saluran 1 Kiri, 2 Kanan, 3 Kanan, dan 5 Kiri tidak memenuhi persyaratan Saluran Eksisting. Maka akan dilakukan perenecanaan ulang saluran yang tidak memenuhi, agar Debit Saluran Eksisting mampu menampung Debit Limpasan yang terjadi. 
Timur

\section{Analisis saluran drainase rencana}

Dilakukan desain ulang untuk saluran eksisting yang tidak mampu menampung debit limpasan pada Tabel 5.

Tabel 5. Analisis saluran rencana

\begin{tabular}{ccccccc}
\hline \multirow{2}{*}{ No } & Posisi & \multicolumn{2}{c}{ Saluran } & $\begin{array}{c}\text { Debit } \\
\text { Limpasan }\end{array}$ & $\begin{array}{c}\text { Debit } \\
\text { Rencana }\end{array}$ & Keterangan \\
\cline { 3 - 5 } & Kebar $(\mathrm{m})$ & Kedalaman $(\mathrm{m})$ & 0,3 & 0,3456 & 0,3852 & MEMENUHI \\
2 & 1 & 0,7 & 0,1082 & 0,1212 & MEMENUHI \\
3 & Kanan & 0,7 & 1 & 0,4638 & 0,5314 & MEMENUHI \\
5 & Kanan & 1 & 1,1 & 0,7085 & 0,7735 & MEMENUHI \\
\hline
\end{tabular}

Dilakukan desain ulang saluran agar debit dari saluran eksisting dapat menampung debit limpasan yang terjadi. Menggunakan metode Trial and Error untuk menentukan dimensi saluran yang akan digunakan, dan perlu dilihat juga kondisi dari saluran sekitarnya. Dari rekapitulasi pada Tabel 5 dapat disimpulkan bahwa saluran rencana dapat digunakan sebagai acuan untuk mendesain ulang saluran eksisting yang tidak mampu menerima debit dari limpasan akibat curah hujan yang terjadi.

\section{Faktor lain penyebab banjir}

Penyebab banjir selain kapasitas saluran dari hasil survey lapangan yaitu:

1. Penyempitan saluran tersier karena adanya pembangunan diatas saluran

2. Banyaknya sedimen sehingga menyebabkan saluran menjadi dangkal

3. Banyaknya sampah yang menghalangi aliran air di saluran.

4. Adanya pasang surut air laut dikarenakan wilayah ini dekat dengan laut.

\section{KESIMPULAN DAN SARAN}

\section{Kesimpulan}

Setelah dilakukan penelitian dapat disimpulkan bahwa kapasitas saluran eksisting tidak dapat menampung curah hujan yang terjadi. Sebanyak 4 dari 17 saluran tidak dapat menampung debit dari curah hujan sehingga harus dilakukan desain ulang. Adanya beberapa faktor lain seperti penyempitan saluran, sedimen, sampah dan letak geografis wilayah juga menjadi penyebab terjadinya genangan di wilayah Pademangan II Gang 22.

\section{Saran}

Dari analisis drainase yang dilakukan, disarankan untuk mendesain ulang saluran di wilayah ini sesuai dengan perhitungan yang telah dilakukan. Pembersihan saluran secara berkala juga diperlukan untuk tetap menjaga aliran air tetap lancar. Peran masyarakat dalam menjaga saluran juga sangat penting, oleh sebab itu harus dilakukan sosialisasi kepada masyarakat.

\section{DAFTAR PUSTAKA}

Astuti, Andina F., dan Hadi Sudarsono. "Analisis Penanggulangan Banjir Sungai Kanci." Jurnal Konstruksi, vol. 7, no. 3, 2020, pp. 163-170.

Wahyuningtyas, Annisa., et al. "Pengendalian Banjir Sungai Bringin Semarang”. Jurnal Karya Teknik Sipil, vol. 6, vo.3, 2017, pp. 161-171.

Ariyani, Dwi. Hidrologi. Universitas Pancasila, Jakarta, 2015.

Badan Standarisasi Nasional. SNI 8456:2017 Sumur dan Parit Resapan Hujan, 2017.

Badan Standarisasi Nasional. SNI 2415:2016 Tata Cara Perhitungan Debit Banjir Rencana, 2016.

Kementerian Pekerjaan Umum. Penyelenggaraan Sistem Drainase Perkotaan 12/PRT/M/2014, 2014.

Suripin. Sistem Drainase Yang Berkelanjutan. Yogyakarta, Andy, 2004.

Haryono, Yosef. Buku Kuliah Drainase. Jakarta, Fakultas Teknik Universitas Tarumanagara, 2016. 